\title{
Resource-Saving Quality Management Systems of Coal Products Using the DSKA-4m Complexes
}

\author{
Victor Atrushkevich ${ }^{1,}$, Nam Bui Juan ${ }^{1}$, Artem Atrushkevich ${ }^{1}$, and Alberto Rodriguez ${ }^{1}$ \\ ${ }^{1}$ The National University of Science and Technology MISiS, 119049 Leninsky avenue, 4, Moscow, \\ Russia
}

\begin{abstract}
The article presents developed and widely implemented processing technologies of mining enterprises (crushing, classification, averaging adjustment screen composition, dehydration, loading, storage, reducing the ash content and moisture source)-based complexes DSKA. Offers innovative technical software allows mining companies and companies to create and consumers, in accordance with fluctuations in the market, to adjust flows of products providing a wide range of quality. Coal crushing and classification equipment is widely used in coal mines, sea and river ports, railway terminals and large coalstorage yards. However, drawbacks of the conventional technologies used in crushing (jaw, cone, rotary and rolling crushers), sizing (on low-frequency high-amplitude screens) and conveying (belt conveyors) worsen efficiency of production and decrease its attractiveness as investment. Besides, the preparation plants in service cannot, as a rule, ensure the integrated and adjustment-flexible approach to providing the desired quality of coal end product.
\end{abstract}

\section{Introduction}

The main tasks of any branch in mining industry, including coal mining, are the higher quality, reduced cost and expanded output of end product [1-3]. Effectivizations of a mining enterprise, as well as improvement of quality and expansion of range of end product are achievable with partial or complete processing of minerals on-site [4-5]. Consequently, underground and open pit coal mines increasingly operate coal preparation facilities [6-7].

Researchers of the Moscow Mining Institute of National University of Science and Technology "MISIS" and experts of the Hydrotechnology Science\&Production Association have developed a fundamentally new technology and equipment for high-performance integrated preparation of coal within the frames of a process flowsheet accepted by a mine [8-9]. The technology allows to variously combining different production methods,

\footnotetext{
*Corresponding author: iugi@mail.ru
} 
including crushing, sizing, washing, dewatering, waste rock removal, combustion of wet and high-ash coal slack concurrently with thermal and electric energy generation.

\section{Experimental research}

Distinctive features of the implementation of the processes of crushing and classification according to the developed technology are an increase (by 30\%) of the output of highquality coal, modularity and flexibility of the design of the complexes, allowing them to be assembled and dismantled, and the number and size of the classes reduced with minimal costs. Various options for loading, storing ordinary and graded coal and loading it into railway wagons can be used. Designs of crushing-classification-loading complexes DSKA (Fig.1-4) allow:

- Coal crushing and classification with capacity of 100 to $3000 \mathrm{t} / \mathrm{h}$ at feedstock size above 1 $\mathrm{m}$;

- Obtaining better sieving of crushed coal for further washing and coking (for metallurgical coal);

- Direct car loading of coal (coarse fractions and screenings);

- Erection and installation on infrastructure sites of underground mines and open pits, sea and river ports, loading sites as well in underground mines.

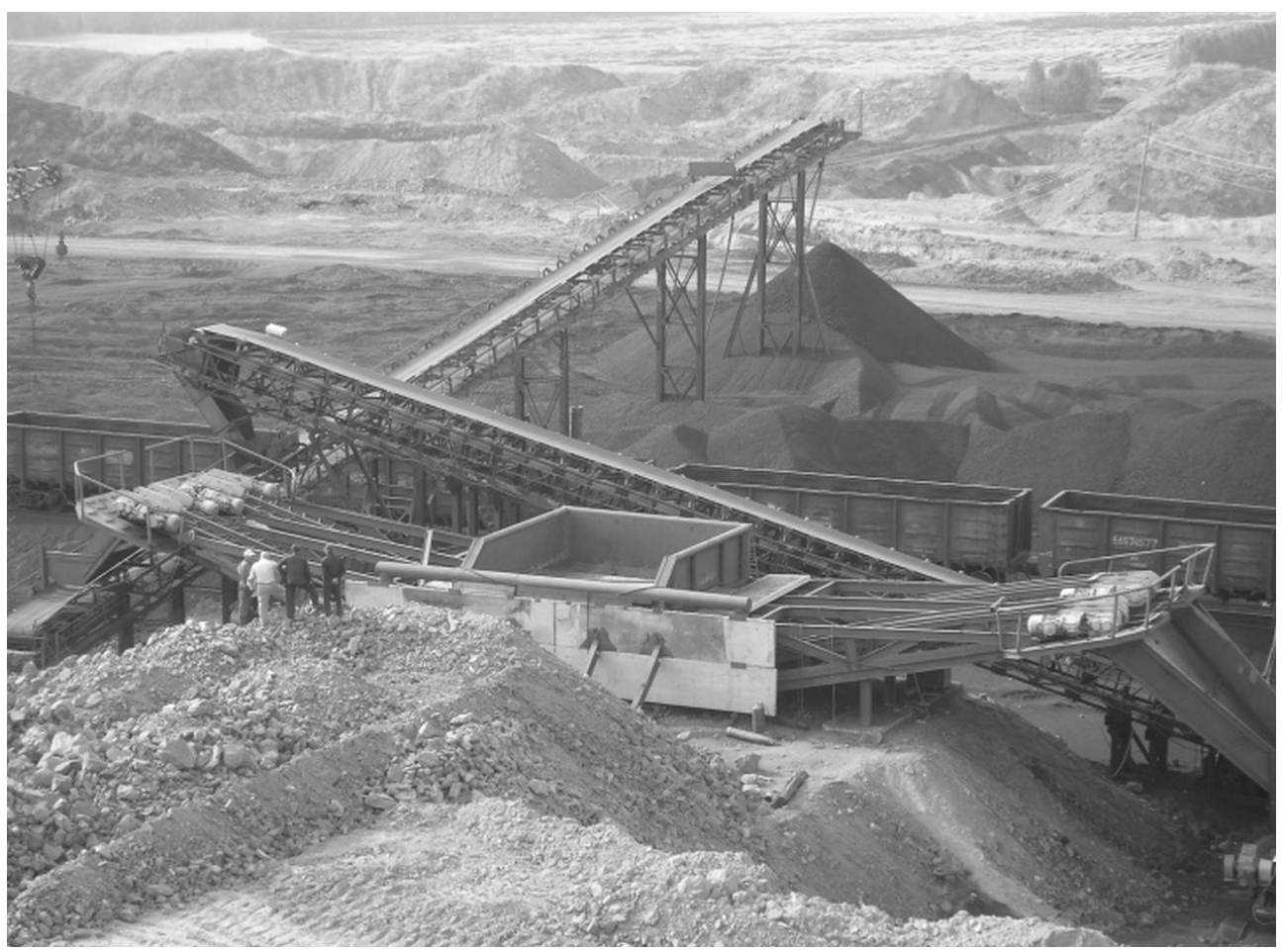

Fig. 1. Design of a DSKA complex, capacity 1500 t/h; Pereyaslavsky open pit mine, Krasnoyarsk. 


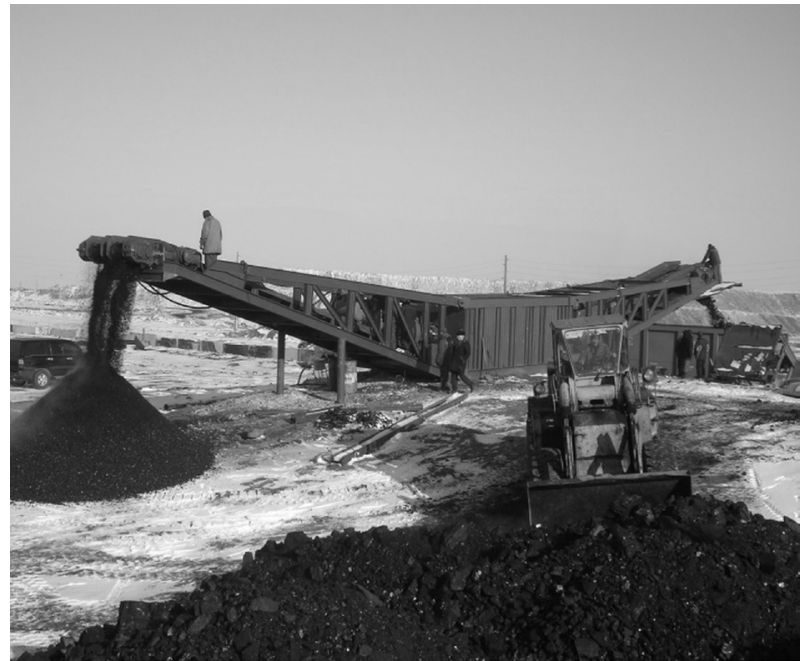

Fig. 2. Design of a DSKA complex, capacity $750 \mathrm{t} / \mathrm{h}$, Karazhyra open pit mine, Kazakhstan.

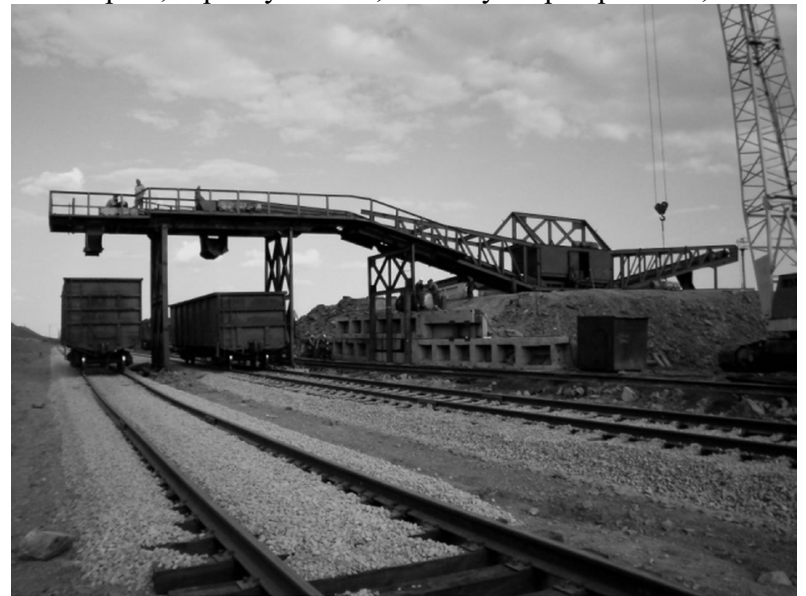

Fig. 3. Design of a DSKA complex, capacity 1000 t/h, Shubarkol Komir Ltd, Kazakhstan.

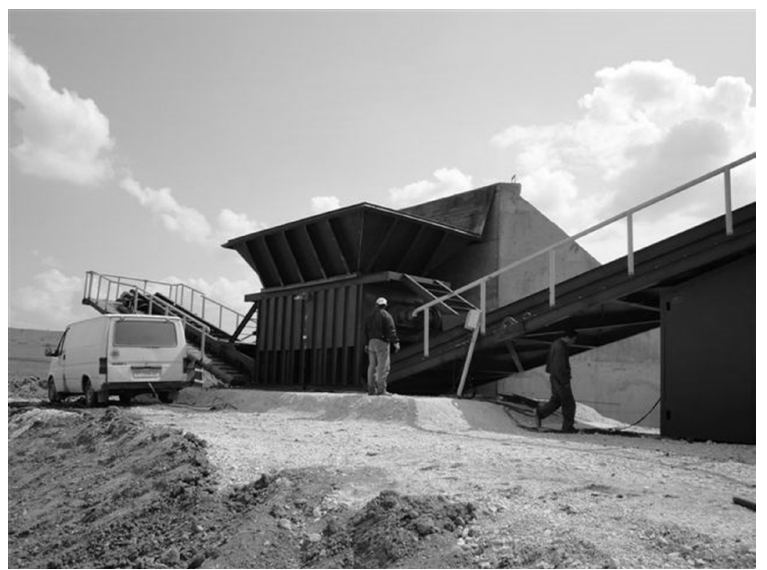

Fig. 4. Design of a DSKA complex, capacity $600 \mathrm{t} / \mathrm{h}$, for one-stage crushing (to $0-25 \mathrm{~mm}$ size) and classification of lignite, Pelister Bitola, Macedonia, 
The described crushing-classification-loading complexes DSKA work as follows. First, run-of-mine coal is fed in a single-roll shearing crusher where coarse coal is only crushed and slack coal formation is minimized. Another feature of this crusher is its capability under "heap," i.e. it can work under source material weight governed by capacity of an inlet hopper. Then, a scraper feeder forwards coal to classification.

In accordance with the developed technology, classification of coal is carried out on scraper conveyors equipped with slotted screens. While conveying coal, the conveyor transmits vibration effect to the screens; frequency and amplitude of vibration is adjustable in conformity with characteristics of the feedstock, amount and coarseness of the sorted size grades. Quality of the classification, i.e. fine coal content in coarse size grades in compliance with the requirements of a consumer, is governed by length of the working surface and other parameters of the scraper conveyors.

The crushing-classification-loading complexes DSKA manufactured by "Hydrotechnology" Science\&Production Association are successfully operated in Kuzbass (Listvyansky and Taldinsky open pit mines, West-Siberian Processing Plant, Siboptprofi Ltd), Kaliningrad (Baltic Coal Company), Krasnoyarsk (Pereyaslavsky and Karabulsky open pit coal mines), Kazakhstan (Borly and Karazhyra open pit mines of the Kazakhmys Corporation, Karaugol Group Ltd and Shubarkul Komir JSC), lignite processing plants in Macedonia and Romania etc, where these complexes have been erected on a turn-key basis and outperformed analogous equipment.

Economic feasibility of DSKA handling is as follows:

Wider production range of marketable coal products (sale at higher prices of coarse graded coal on the domestic and foreign markets, for instance, for public services or different industry branches, e.g. chemical production, where certain size grades of coal are required);

Reduced expenditures connected with car loading of coal and arrangement of additional loading terminals;

Great reduction of cost of coal warehousing, transloading and handling owing to the continuous conveyance equipment (various conveyor systems and loaders);

Vantage of multifunctionality, modularity,high adaptability and flexibility of the technology;

Improved quality and optimized price of coal product due to decreased ash content of the screening.

In support of the aforesaid, operation experience of a DSKA complex in Karazhyra open pit mine (Kazakhstan) resulted in screening ash content of $12 \%$ as compared with ROM coal ash content of $18 \%$, which makes up $33 \%$ reduction of the ash content. Waste rock, if gets in a coarse size grade, can be removed mechanically (technology developed by Gidrougol NPO Ltd), using pneumatic cleaning equipment (SEPAIR technology, FGX separators made in China), or effective and well-priced manual removal installation designed by Hydrotechnology Science\&Production Association and successfully run by Karaugol Group Ltd in Kazakhstan.

Combining the DSKA complexes and heavy-density coal washing equipment allows better screening quality, lower ash content and cut-down cost of dense medium removal. A proprietory continuous heavy-density separation system based on scraper conveyors has been developed and offered for use.

In 2011 the present paper authors have implemented a new technology of "non-thermal drying" of lignite based on a DSKA complex in Romania (Figure 5). After crushing, lignite is fed, mechanically or air-driven (dynamic shock action on crushed coal in air flow), to a specifically formed "high-porous" warehouse. In the course of processing and short-term warehousing, humidity of coal product greatly decreases. 


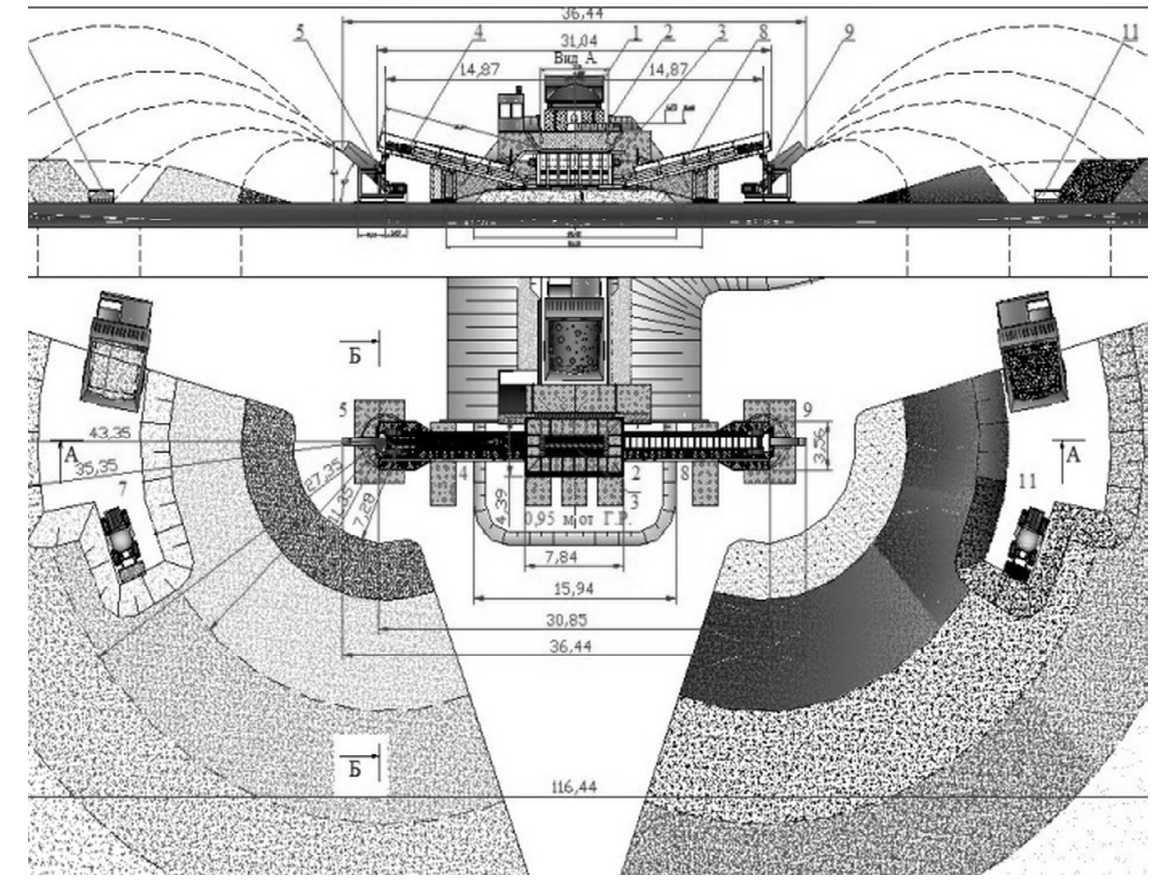

Fig. 5. DSKA complex for lignite crushing, classification and dehumidification, designed for open pit mine in Romania.

Thus and so, application of DSKA complexes allows for appreciable reduction of ash content and moisture of coal, which means higher calorific power and price of the end product.

The price of the DSKA complexes, depending on size, is several times lower as against the similar equipment present on the world market. Productiveness, amount of size grades required and price of a DSKA complex are adjustable in conformity with the actual or expected outputs of coal processing at a mine site. These characteristics may be changed in upgrading the DSKA complex on-stream. It is even possible to redesign the complex subject to a certain kind (grade) of coal product.

The reason for application the offered resource-saving technology in coal mining and processing is the achievability of high efficient crushing and classification of coal for power engineering, and cost-saving of charge material in case of metallurgical coal. DSKA complexes compare favorably with the similar equipment due to lower price, availability of spare parts, high performance, easy servicing, as well as higher yield of quality size grades and screening, which ensures better dressability and cokeability of coal. Currently, the described technology is introduced on European and Asia-Pacific markets (www.timetehno.ru).

\section{Results and discussion}

A fundamentally new technology and equipment for complex processing of coals in the technological systems of the mining enterprises was implemented. The technology provides for the possibility of implementing a different set of technological processes, including: crushing, classification, moisture reduction, non-thermal drying, removal of large rock, burning of moist and high-ash fractions to produce heat and electricity. The developed equipment in comparison with the analogs has the ability to: 
- produce a one-stage crushing and sorting of coal with a capacity of up to 3000 tons per hour with a coarse particle size of the original coal of more than one meter;

- reduce costs and increase by a third the output of high-quality coal of large fractions; to crush and separate coals in one installation for any number of fractions;

- significantly reduce the amount of fines in large fractions of coal;

- carry out the classification of wet coals, including - with a clay component;

- reduce the ash content of coal (removal of the rock during crushing, the possibility of obtaining washed coal);

- provide the best structure for the enrichment (coking) of the sieving of the crushing products;

- increase the export attractiveness of mining products;

- Minimize dependence on availability of spare parts and services in the region, due to the simplicity and reliability of the design;

- to make coal loading by motor transport and unloading coal into railway cars; to install them in coal storages, loading stations, in open and underground mines of mining enterprises.

\section{Conclusion}

The developed and widely applied technologies (crushing, screening, blending, sieve analysis, dewatering, loading, warehousing, ash content reduction, moisture reduction, drying) coupled with DSKA complexes allow for mining companies and consumers to arrange and vary, in accord with economic fluctuations, the end product streams (coal, gypsum, graphite, sand, limestone, bauxites, etc) in a wide guaranteed quality range.

At present, our company (Hydrotechnology Science\&Production Association) negotiates with interested companies for delivery of the crushing-classification-loading complexes and upgrading of mining and processing enterprises in different regions over the world, as consistent with the described technologies and engineering solutions.

\section{References}

1. T. Gvozdkova, M. Tyulenev, S. Zhironkin, V. A. Trifonov, Yu. M. Osipov, IOP Conference Series: Earth and Environmental Science, 50:1, 012010 (2017)

2. S. Zhironkin, M. Gasanov, G. Barysheva, K. Kolotov, O. Zhironkina, E3S Web of Conferences, 15, 03012 (2017)

3. A. B. Efremenkov, A. A. Khoreshok, S. A. Zhironkin, A. V. Myaskov, IOP Conference Series: Earth and Environmental Science, 50:1, 012009 (2017)

4. M. Cehlár, L. Mihok, Theoretical and Empirical Researches in Urban Management, 8:4, 60-72 (2013)

5. S. A. Zhironkin, Ugol', 4, 29-31 (2001)

6. A.V. Leszczynski, E. B. Shevkun, J. Mining machines and equipment, 3, 38 (2005)

7. O. A. Atrushkevich, V. A. Atrushkevich, Sat. Works of the XV Balkan Congress on the Enrichment of Minerals, 1046 (2013)

8. O. A. Atrushkevich, V. A. Atrushkevich, Sat. Works of the II International Conference Achievements in Mining and Tunneling, 546 (2014)

9. O. A. Atrushkevich, V. A. Atrushkevich, Annual Bulletin of Works Archive of Technical Sciences 10, 46 (2014) 